\title{
CIRRIG: Weather-based Irrigation Management Program for Container Nurseries
}

\author{
Jeff B. Million ${ }^{1}$ and T.H. Yeager
}

\begin{abstract}
ADDITIONAL INDEX WORDS. automation, evapotranspiration, percent plant cover, programmable logic controller, sprinkler

SUMMARY. A goal of irrigation best management practices in container nurseries is to conserve water while maintaining optimal plant growth and quality. A web-based, container irrigation management program (CIRRIG) was developed to automatically provide daily irrigation run times for sprinkler-irrigated crops in container nurseries. The program estimates evapotranspiration rates based on weather uploaded from a weather station located on-site and plant production conditions monitored in each zone and adjusts irrigation run times based on irrigation application rate, the plant's irrigation-capturing ability (for sprinkler irrigation), desired leaching fraction, and irrigation system uniformity. For this project we interfaced CIRRIG output with a programmable logic controller (PLC) to automatically irrigate a sprinkler-irrigated crop at a container nursery in Florida. Sweet viburnum (Viburnum odoratissimum) in 10-inch-diameter containers were grown by the nursery for 24 weeks in adjacent irrigation zones, one controlled automatically using CIRRIG and the other by the nursery's traditional practice of manually turning on and off irrigation. Water use was monitored with flowmeters and plant growth by measuring plant size and shoot dry weight periodically throughout the trial. Plant growth was not different $(P<0.05)$ because of irrigation practice. CIRRIG reduced water use during the study period by $21 \%$ (42 vs. 53 inches) compared with the nursery's irrigation practice. An assessment of the watersaving benefits of making daily adjustments to irrigation run times based on weather including rain indicated savings of $25 \%$ and $40 \%$ compared with biweekly adjustments with and without automatic rain cutoff, respectively. This trial demonstrated that CIRRIG coupled with an on-site weather station and computer-controlled irrigation system can be used to manage irrigation while conserving water in a container nursery.
\end{abstract}

$\mathrm{D}$ etermining irrigation run times that minimize water use while sustaining optimal production is a difficult task for container nursery managers. This is particularly true for production in small containers as conditions in the irrigated area that affect evapotranspiration (ET) rates (e.g., plant growth, pruning, spacing) can change rapidly compared with microirrigated plants grown in large containers. Furthermore, the capture of sprinkler irrigation water can be greatly affected by the plant canopy so that crops with similar ET rates may require different irrigation rates (Million and Yeager, 2015). The dynamic natures of ET and irrigation capture provide great

Department of Environmental Horticulture, Institute of Food and Agricultural Sciences, University of Florida, 1545 Fifield Hall, Gainesville, FL 326110670

This research was sponsored by a grant from the Southwest Florida Water Management District (SWFWMD Project no. B29l)

Trademarks mentioned for informational purposes do not constitute an endorsement.

${ }^{1}$ Corresponding author. E-mail: jmillion@ufl.edu. challenges for ET-based irrigation scheduling.

Several systems are being used to implement ET-based irrigation in container nurseries. One approach is to directly monitor substrate moisture content with sensors (Kohanbash et al., 2013; van Iersel et al., 2013). Sensors can be programmed to open solenoid valves when substrate moisture falls below critical values and then to close valves once favorable substrate moisture thresholds are reached. Sensor-based irrigation has the distinct advantage of directly monitoring the water status of the container substrate. A disadvantage of sensor-based irrigation is the cost for purchasing, installing, and maintaining a sensor network in the nursery. However, as the technology improves, this approach will become less expensive and easier to use and manage (Belayneh et al., 2013).

Another means for implementing ET-based irrigation, and one used in this research, is a software approach whereby substrate water loss is estimated with ET functions. A general function used to estimate ET for a wide range of agricultural crops entails multiplying potential ET (ETo) by a crop coefficient to determine actual ET (Schuch and Burger, 1997). Because crop coefficients depend on rapidly changing growing conditions, continuous functions have been developed to estimate actual crop ET rates $(\mathrm{ETc})$ from ETo (Beeson, 2005, 2010; Grant et al., 2012; Irmak, 2005; Pardossi et al., 2008). For example, Beeson (2010) developed ET functions that use projected plant area and a growth index to estimate ETc from ETo. Million et al. (2011), using a partial cover function developed by Ritchie (1972) for field crops, estimated ETc as a function of ETo and leaf area index. Unlike field crop situations, partial cover in container nurseries can result in significant temperature increases when solar radiation not intercepted by the plant canopy heats nonradiating black container sidewalls and ground-cloth surfaces. To account for the heating effect, Million et al. (2011) used a biased maximum daily temperature in their ETo calculation.

Another source of variation when estimating the irrigation requirement using an indirect approach is the influence that the plant canopy can have on the capture of sprinkler irrigation water. We define the capture factor (CF) as the amount of

\begin{tabular}{llll}
\hline $\begin{array}{l}\text { Units } \\
\text { To convert U.S. to SI, } \\
\text { multiply by }\end{array}$ & U.S. unit & SI unit & $\begin{array}{l}\text { To convert SI to U.S., } \\
\text { multiply by }\end{array}$ \\
\hline 0.4047 & $\mathrm{acre}(\mathrm{s})$ & $\mathrm{ha}$ & 2.4711 \\
0.3048 & $\mathrm{ft}$ & $\mathrm{m}$ & 3.2808 \\
3.7854 & $\mathrm{gal}$ & $\mathrm{L}$ & 0.2642 \\
2.54 & inch $(\mathrm{es})$ & $\mathrm{cm}$ & 0.3937 \\
0.5933 & $\mathrm{lb} / \mathrm{yard}^{3}$ & $\mathrm{~kg} \cdot \mathrm{m}^{-3}$ & 1.6856 \\
28.3495 & $\mathrm{Oz}$ & $\mathrm{g}$ & 0.0353 \\
6.8948 & $\mathrm{psi}$ & $\mathrm{kPa}$ & 0.1450 \\
10.7639 & $\mathrm{~W} / \mathrm{ft}^{2}$ & $\mathrm{~W} \cdot \mathrm{m}^{-2}$ & 0.0929 \\
$\left({ }^{\circ} \mathrm{F}-32\right) \div 1.8$ & ${ }^{\circ} \mathrm{F}$ & ${ }^{\circ} \mathrm{C}$ & $\left({ }^{\circ} \mathrm{C} \times 1.8\right)+32$
\end{tabular}


sprinkler irrigation water captured by the container with a plant relative to that amount of water that would be captured without a plant. CF $>1$ indicates that the plant canopy is augmenting irrigation capture so that irrigation amounts can be reduced accordingly. Similarly, CF $<1$ indicates that the plant canopy is reducing irrigation capture and irrigation amounts would need to be increased accordingly. Functions for estimating CF based on plant size, container size and spacing, and the plant species' watercapturing ability were reported by Million and Yeager (2015).

Using a software approach for indirectly estimating the irrigation requirement for sprinkler-irrigated container crops, daily irrigation run times can be output by estimating ETc and $\mathrm{CF}$ and then calculating the irrigation run time that will deliver the required amount of water to the container, taking into account any rain received. The advantage of a software approach is that no hardware is required except a weather station. A disadvantage of the software approach compared with a sensor-based system is that irrigation run times are indirectly estimated and therefore a degree of uncertainty always exists. Both approaches require labor to either monitor sensor function (sensor approach) or to monitor plant conditions in the irrigated area that affect ET and $\mathrm{CF}$ estimation (software approach).

The purpose of this study was to evaluate an irrigation management program, CIRRIG, for implementing ET-based irrigation in a container nursery. In the first section, we describe CIRRIG and discuss the required inputs to be monitored by nursery staff. In the second section, we describe how the program was used to automatically control an irrigation valve in a nursery and compare water savings of the program with the nursery's traditional irrigation practice. Using results from the trial, we also evaluated the benefit of adopting a weather-based irrigation management program that adjusts run times daily compared with a periodically adjusted irrigation management practice.

\section{Materials and methods}

CirRIg DESCRIPTION. CIRRIG (University of Florida, 2015) is an irrigation management program that

\begin{tabular}{|c|c|c|c|}
\hline \multirow[b]{2}{*}{ Zone Name: } & & \multirow[b]{2}{*}{ Zone Number: } & \\
\hline & A14 & & 7 \\
\hline Plant Name: & Azalea & Zone Type: & ET-sprinkler \\
\hline $\begin{array}{l}\text { External } \\
\text { Reference: }\end{array}$ & 111 & & \\
\hline
\end{tabular}
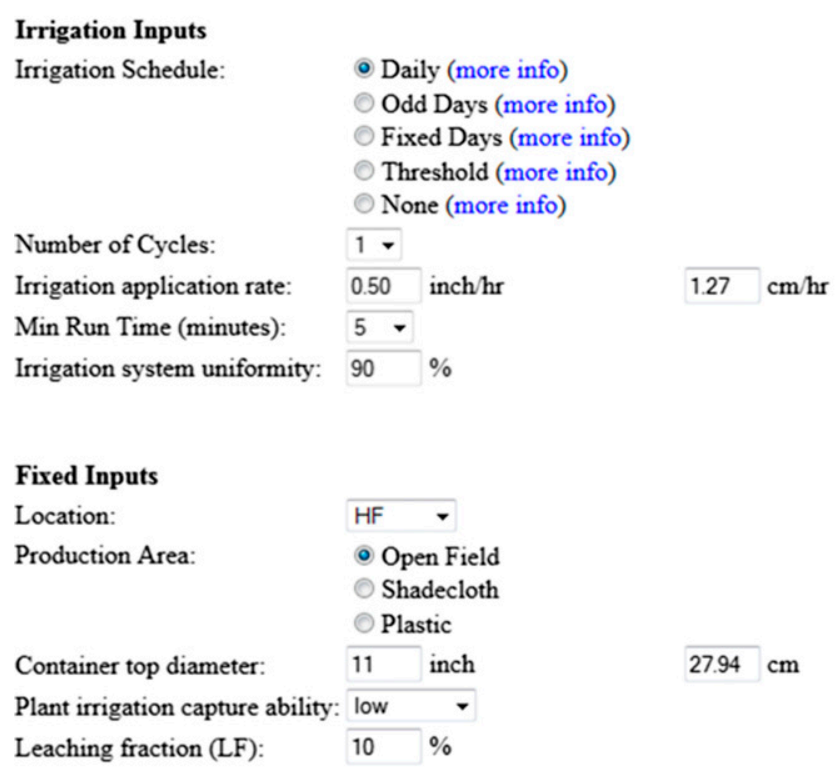

$27.94 \mathrm{~cm}$

\begin{tabular}{|c|c|c|c|c|}
\hline \multicolumn{5}{|c|}{ Infrequently or Slowly-Changing Inputs } \\
\hline \multicolumn{5}{|c|}{ Last changed: $2015-03-2616: 02: 08$} \\
\hline Percent plant cover: & 35 & $\%$ & & \\
\hline Plant height: & 14 & inch & 35.56 & $\mathrm{~cm}$ \\
\hline Plant width: & 12 & inch & 30.48 & $\mathrm{~cm}$ \\
\hline Container spacing: & 8 & inch & 20.32 & $\mathrm{~cm}$ \\
\hline Spacing arrangement: & offset & 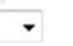 & & \\
\hline
\end{tabular}

Fig. 1. Example computer screenshot of zone input page of CIRRIG, a weatherbased, irrigation management program for container nurseries. Plant production conditions in the irrigation zone are updated periodically as plant size or container spacing changes.

was developed at the University of Florida for container nurseries in the humid southeastern states; its applicability in other regions and other climates has not been tested. All CIRRIG programs and user account data currently reside on a dedicated server located at the Department of Environmental Horticulture in Gainesville, FL. CIRRIG uses weather data acquired from a weather station on-site and plant production conditions to automatically output daily irrigation run times for each irrigation zone created by the user. Hourly weather data are uploaded to the user's account on the server using a Java agent residing on a host computer connected to the weather station. Hourly weather data uploaded to the server includes temperature maximum, temperature minimum, solar radiation, and rain. CIRRIG allows the user to view historical hourly and daily weather data. Required plant production-related inputs for each zone include percent plant cover, container diameter, container spacing, plant height and width, irrigation-capturing ability of plant, and irrigation application rate (Fig. 1). Additional options for adjusting irrigation include irrigation distribution of uniformity [DU (Burt et al., 1997)] and a target leaching fraction. Because CIRRIG estimates daily container ET on 24-h day basis, we partition daily estimated ET rates into hourly ET rates based on the hourly distribution of solar radiation. CIRRIG then balances estimated hourly ET water loss and hourly rain 
input to arrive at a net water deficit for calculating irrigation demand.

The user selects the irrigation schedule for each zone. Schedule options include daily irrigation, odd day irrigation, and fixed day irrigation (particular days of the week). If a nondaily schedule is selected, the water deficit in the container substrate is carried over each day that irrigation is not scheduled.

At a user-selected time, typically just before irrigation, CIRRIG calculates the irrigation run time based on the past 24-h weather and the latest plant production-related inputs for each zone. Besides irrigation run time, displayed output also includes supportive information including estimated $\mathrm{ET}, \mathrm{CF}$, irrigation rate, and weather data. Historical zone output can also be viewed for a user-selected period. Output can be viewed on a computer or mobile device or exported in a comma-delimited $\left({ }^{*}\right.$.csv $)$ file for automation. For automation, the user assigns an external reference (e.g., valve number) to each zone and this reference is output in the ${ }^{*}$.csv file to enable interfacing with the nursery's own computer-controlled irrigation system. We developed a Java program for the client side to manage the daily download of the * .csv file. The nursery will then need to develop its own program to incorporate the ${ }^{*}$.csv file data into the database associated with the nursery's computer-controlled irrigation system. For our own research purposes, we developed a Java program that directly acquired irrigation run times from CIRRIG and set timer values on our PLC thereby eliminating the need to download a *.csv file.

Field Demonstration trial. CIRRIG technology was evaluated at Salmon's Wholesale Nursery (SWN), a 70-acre container nursery located in Dunnellon, FL (lat. $82.5^{\circ} \mathrm{W}$, long. $29.0^{\circ} \mathrm{N}$ ). Two adjacent independently controlled irrigation zones in the nursery were selected to compare water use and plant growth of container shrubs produced with either the nursery's traditional irrigation practice or with CIRRIG. The irrigation system used at SWN was manually turned on and off by nursery staff. Once turned on, the system automatically cycled (typically one to three cycles per zone) through all irrigation zones until turned off. Because they did not use traditional time clocks to set the irrigation schedule, start times and run times varied daily.

Several tasks were required to implement CIRRIG at the nursery. A weather station (Vantage Pro2 Plus ${ }^{\circledR}$; Davis Instruments ${ }^{\circledR}$, Hayward, CA) was installed $50 \mathrm{ft}$ from a shed that housed the nursery's irrigation electrical hardware. The station was attached to a tripod so that the fanaspirated radiation shield was $5 \mathrm{ft}$ above the ground. Cabling was run from the weather station to the data-logging console located inside the shed. The data logger recorded hourly weather data that was automatically downloaded via a USB connection to a laptop computer using proprietary software (Weatherlink ${ }^{\circledR}$, Davis Instruments $\left.{ }^{\circledR}\right)$. Weatherlink was configured to automatically export hourly weather data to a text file that was uploaded hourly to the CIRRIG server via a Java program residing on the laptop. Weather data logged at the top of the hour was downloaded to the computer $5 \mathrm{~min}$ past the hour and uploaded to CIRRIG at 10 min past the hour.

A second task was to setup an internet connection in the remotely located irrigation shed. For this, we used an USB cellular modem (UML290 4G USB; Pantech Mobile, Atlanta, GA) connected to a wireless router (BR95; Cradlepoint, Boise, ID). A static IP address was acquired (Verizon Wireless, Wallingford, CT) to enable a constant internet connection.

Another task was to install a PLC to serve as a computer-controlled irrigation system that could interface with CIRRIG. A PLC (D0-06DA; Automation Direct, Cumming, GA) with an Ethernet communications module was installed in the irrigation shed. The PLC was configured for the static IP address to allow constant connectivity. A graphical user interface (GUI) for controlling the PLC remotely was developed to allow us to manage the acquisition of CIRRIG output by the PLC as well as monitor real-time PLC activity. The GUI also had functions for manually controlling irrigation or for setting default irrigation run times if internet connection was lost. PLC irrigation history was archived in a text file that could be monitored remotely. To complete the PLC system, wires to the solenoid valve controlling one of the two irrigated zones were rerouted to the PLC leaving the other test area on the nursery's system. Because we could not use the nursery's $24-\mathrm{V}$ AC circuit, we installed a $24-\mathrm{V}$ AC transformer to supply electrical current for the PLC-controlled circuit.

The two irrigation zones selected for testing were each $85 \times 225 \mathrm{ft}$. Water from 3 -inch supply lines were distributed through $1^{1} / 4$-inch pipes to 34 sprinklers per zone on risers $5 \mathrm{ft}$ tall. Sprinklers (Xcel-Wobbler highangle; Senninger ${ }^{\circledR}$ Irrigation, Clermont, FL) were fitted with \#9 (grey) nozzles rated at $2.5 \mathrm{gal} / \mathrm{min}$ at $20 \mathrm{psi}$. Sprinklers were arranged in four rows $25 \mathrm{ft}$ apart in an offset pattern. The irrigation application rate was 0.43 inch/h and DU was $>90 \%$. Flow meters $\left(\mathrm{Omni}^{\mathrm{TM}} \mathrm{T}^{2}\right.$; Sensus ${ }^{\circledR}$, Raleigh, $\mathrm{NC})$ were installed in each of the 3 inch-diameter pipes supplying the two test zones to monitor and compare water amounts applied to each of the two irrigation zones during the trial. The relationship between flowmeter readings in gallons to irrigation depth in inches was determined by collecting irrigation water in twenty 4-inch-diameter containers over a 10-d period. Based on these tests, the average ratio of inches of irrigation to gallons of water flow was used to convert flowmeter readings to depth of irrigation water.

On 4 Dec. 2013, 1280 rooted cuttings of sweet viburnum were transplanted by nursery staff into 10-inch-diameter containers (Classic 1000; Nursery Supplies ${ }^{\circledR}$, Kissimmee, FL) filled with a substrate mix comprised by volume of 5.5 pine bark: 4.5 Florida sedge peat: 1 sand and amended with gypsum at $3 \mathrm{lb} /$ yard $^{3}$ and a $0 \mathrm{~N}-0 \mathrm{P}-5.0 \mathrm{~K}$ fertilizer with minor elements at $2 \mathrm{lb} /$ yard $^{3}$ (Reliable Peat, Leesburg, FL). An $18 \mathrm{~N}-$ 2.2P-7.5K, resin-coated, controlledrelease fertilizer Osmocote $^{\circledR}$ Pro 18-5-9 with micronutrients, 11-12 month release at $70^{\circ} \mathrm{F}$; Everris, Dublin, $\mathrm{OH}$ ) was placed underneath each transplanted cutting at the time of planting at the rate of $16 \mathrm{~g}$ per container. Containers were placed outdoors on black, woven, polypropylene ground-cloth in an offset pattern with no spacing between adjacent containers. Plants were equally distributed across the two test irrigation zones. Additional species planted and placed in the two test 
irrigation zones included japanese privet (Ligustrum japonicum), yellow anisetree (Illicium parviflorum), jack frost privet (Ligustrum japonicum), and chinese fringe flower (Loropetalum chinense var. rubrum). From planting until the initiation of the trial, SWN staff controlled all irrigation. Plants were covered with cold protection cloth as needed by nursery staff during the same time period.

On 4 Mar. 2014, 80 plants in each test zone were grouped into five blocks of 16 plants. The 16 plants within each block were randomly assigned to one of four harvest dates in 2014: 7 Mar., 5 May, 30 June, and $28 \mathrm{Aug}$. On harvest dates, biomass of plant shoots was determined by cutting plants at the substrate surface and drying shoots in a forced-air dryer at $70{ }^{\circ} \mathrm{C}$ for $48 \mathrm{~h}$. Plant size measurements of the final harvest plants were taken biweekly throughout the trial. Plant height was measured from the substrate surface to the uppermost foliage while plant width was the average of two perpendicular measurements, one being the widest.

All production activities (except irrigation management in the CIRRIG zone) were conducted by nursery staff. Nursery staff applied preemergence herbicide $\left(\mathrm{OH} 2^{\circledR}\right.$; Everris, Dublin, $\mathrm{OH}$ ) to all plants on 28 April Controlled-release $21 \mathrm{~N}-$ 1.7P-6.7K fertilizer (Nursery Mix 21-4-8; Everris, Dublin, $\mathrm{OH}$ ) was surface-applied at $45 \mathrm{~g}$ per container on 8 May. Plants were pruned on 6 June by removing 9-10 inches of plant height and 2-3 inches of plant width. On 10 July containers were spaced 12 inches apart by nursery staff.

The irrigation trial began on 11 Mar. 2014. Flowmeter readings of each test zone were taken on 11 Mar. and at least once per week throughout the 6-month trial. Irrigation of the CIRRIG zone was managed by University of Florida staff. Irrigation in the CIRRIG zone was typically scheduled for $0630 \mathrm{HR}$ while irrigation in the SWN zone was typically scheduled for $1630 \mathrm{HR}$ or later. About once every 2-3 weeks, plant production inputs required for CIRRIG were monitored. Percent plant cover (PPC) was determined throughout production by taking digital images $4 \mathrm{ft}$ above the canopy of each block of plants and estimating PPC

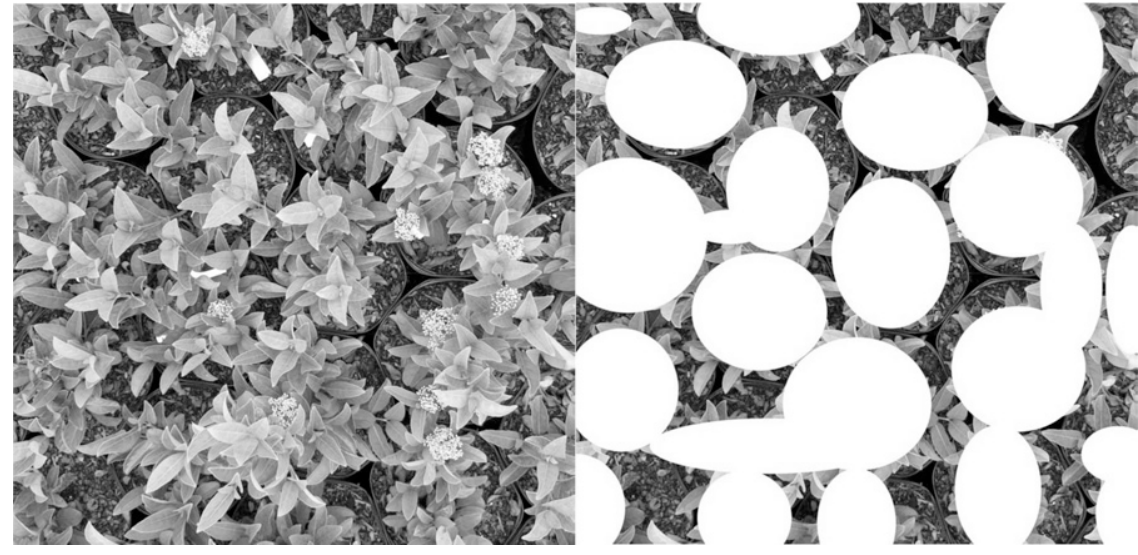

Fig. 2. An image processing program was used to estimate percent plant cover (PPC), a required input of irrigation management program. A selection tool was used to delete dense foliage and the percentage of white pixels to total pixels in the image using a histogram provided an estimate of PPC, $65 \%$ in this example.

using image processing freeware (GNU Image Manipulation Program, 2015). With GIMP, dense green foliage was selected using an oval selection tool then deleted turning selected pixels to white. The result was a processed image with white areas where dense foliage was deleted (Fig. 2). The percentage of white pixels to total pixels as determined by GIMP's histogram tool provided an estimate of PPC. The average PPC of the five images was input into CIRRIG. Percent plant canopy cover was determined in the same manner throughout production as plants grew in size and/or plants were pruned or spaced.

The effect of irrigation on plant size index and shoot dry weight at each measurement date was evaluated using a paired $t$ test with $\mathrm{n}=20$ and a confidence level of $5 \%$ (SAS version 9.2; SAS Institute, Cary, NC). Cumulative water use by the two irrigation practices as measured by flowmeters could not be compared statistically. We report both a cumulative depth of irrigation water applied as well as amounts applied between successive flowmeter reading dates.

An additional analysis of the potential benefits of using a weatherbased irrigation program vs. a fixedrate program was made by dividing the trial into twenty-four 2 -week intervals and comparing the depth of water applied with CIRRIG to two hypothetical fixed-rate irrigation schedules. One fixed-rate schedule took the maximum daily irrigation amount applied during a given 2 -week interval (according to CIRRIG) and applied this amount each day during the same 2 -week interval. A second fixed-rate schedule was the same as the first except no irrigation was applied if 0.5 inch or more rain fell on the previous day.

\section{Results and discussion}

Plant size index (Fig. 3) and shoot dry weight (Fig. 4) were not different $(P>0.05)$ because of irrigation schedule. Plant height and width were 10 and 9 inches, respectively, at the start of the experiment and 27 and 24 inches, respectively, at the end of the trial. Plants grew well throughout the trial with only the June pruning resulting in a decrease in plant size and shoot biomass.

Cumulative irrigation water applied during the trial was 42.1 and 53.0 inches for the CIRRIG and SWN schedules, respectively. The $21 \%$ reduction in cumulative water use when irrigation was automatically controlled using CIRRIG was relatively constant throughout production (Fig. 5). Higher water use by SWN may be due in part to reduced efficiency of getting irrigation water into the container in the afternoon when evaporative losses were likely higher compared with CIRRIG's early morning application when evaporative losses would be expected to be lower (Playan et al., 2005). The linear shape of the cumulative water use plots indicate that irrigation amounts did not change significantly during the trial despite increased plant growth. The reason for this was that CF increased in proportion to 


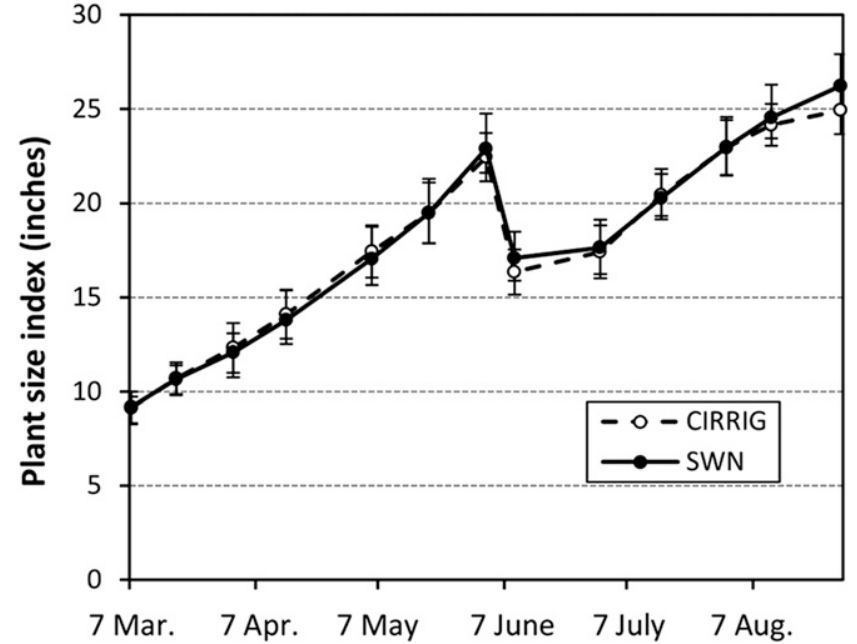

Fig. 3. Plant size index of sweet viburnum in 10-inch-diameter containers irrigated automatically with a weather-based irrigation program (CIRRIG) or manually according to the nursery's traditional irrigation practice (SWN). Plant size index = (plant height + plant width $) \div 2$, error bars are $\pm S D(n=20), 1$ inch $=2.54 \mathrm{~cm}$.

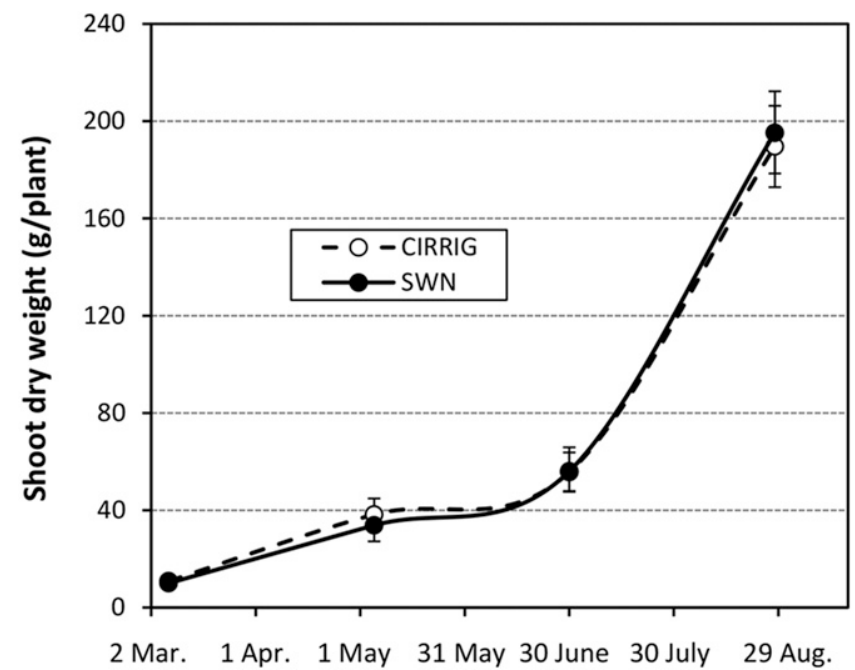

Fig. 4. Shoot dry weight of sweet viburnum in 10 -inch-diameter $(25.4 \mathrm{~cm})$ containers irrigated automatically with a weather-based irrigation program (CIRRIG) or manually according to the nursery's traditional irrigation practice $(S W N)$; error bars $= \pm S D(n=20), 1 \mathrm{~g}=0.0353 \mathrm{oz}$.

increases in ET. For example, ETc and $\mathrm{CF}$ measured on 1 April were 0.23 inch and 1.2, respectively, and when measured on 12 July were 0.51 inch and 2.5, respectively. In this case, ETc increased $2.2 \times$ but at the same time $\mathrm{CF}$ increased $2.1 \times$. A similar increase in $\mathrm{CF}$ was reported for sweet viburnum produced in 6.3-inchdiameter containers (Million et al., 2010).

A comparison of the irrigation water applied by the two irrigation programs on an interval basis shows that SWN staff had a remarkable ability to increase and decrease irrigation in a similar pattern as CIRRIG
(Fig. 6). We attributed this in part to SWN's irrigation system which required staff to manually turn on and off the irrigation system each day so that irrigation run times were determined on a day-to-day basis based on apparent need. For intervals where CIRRIG reduced irrigation, SWN also reduced irrigation, often to the same extent. For intervals where irrigation amounts peaked for SWN, CIRRIG also peaked but often at much reduced amount. For example, two peaks in May when little rain occurred (Fig. 7 ) indicated that CIRRIG applied $25 \%$ to $60 \%$ less water. Compared with peak interval irrigation water use in May and June, peak interval irrigation in July and August decreased, which was because of increased rainfall and decreased solar radiation levels that coincided with afternoon cloud formation typical of that time of the year.

The nursery's method of manually turning on and off irrigation is in contrast to many growers who set irrigation time clocks to apply a fixed amount of water. In many situations, irrigation run times are not changed for weeks or months at a time. To get some perspective of how CIRRIG in the present trial might compare with a fixed-rate schedule, we compared CIRRIG water use to the water use that would have occurred with two fixed-rate programs, one that accounted for rain (FIXED-RAIN) and one that did not (FIXED). Because the fixed rate of irrigation for both FIXED and FIXED-RAIN was the maximum daily amount applied during each 2 -week interval, the daily fixed rate of irrigation was changed once every 2 weeks. The benefit of using CIRRIG, which made daily adjustments in irrigation based on the past day's weather, is depicted in Fig. 8. CIRRIG reduced cumulative irrigation water applied 40\% (37 vs. 62 inches) when compared with FIXED and $25 \%$ ( 37 vs. 50 inches) when compared with FIXED-RAIN. FIXED-RAIN reduced cumulative irrigation water applied 20\% (50 vs. 62 inches) compared with FIXED providing evidence that turning off irrigation after significant rain is an important conservation practice.

Compared with using a traditional rain sensor to cutoff irrigation, CIRRIG had the added advantage of objectively evaluating rain quantity and timing relative to any water deficit. During the trial, total rainfall was 27.8 inches. According to CIRRIG, only 8.5 inches or $31 \%$ of total rain directly reduced irrigation during the trial. Interestingly, for the $21 \mathrm{~d}$ that it rained $\geq 0.5$ inch, only $17 \%$ (3.8 vs. 21.8 inches) of rain effectively replaced the irrigation requirement. The low percentage was due in part to the fact that many of the rain events of $\geq 0.5$ inch occurred toward the end of the season when $\mathrm{CF}>2$ and ET rarely exceeded 0.8 inches. Also, 7 of the $21 \mathrm{~d}$ received $>1.0$ inch and on those days ET rates were low because of low solar radiation levels. For the $34 \mathrm{~d}$ that 


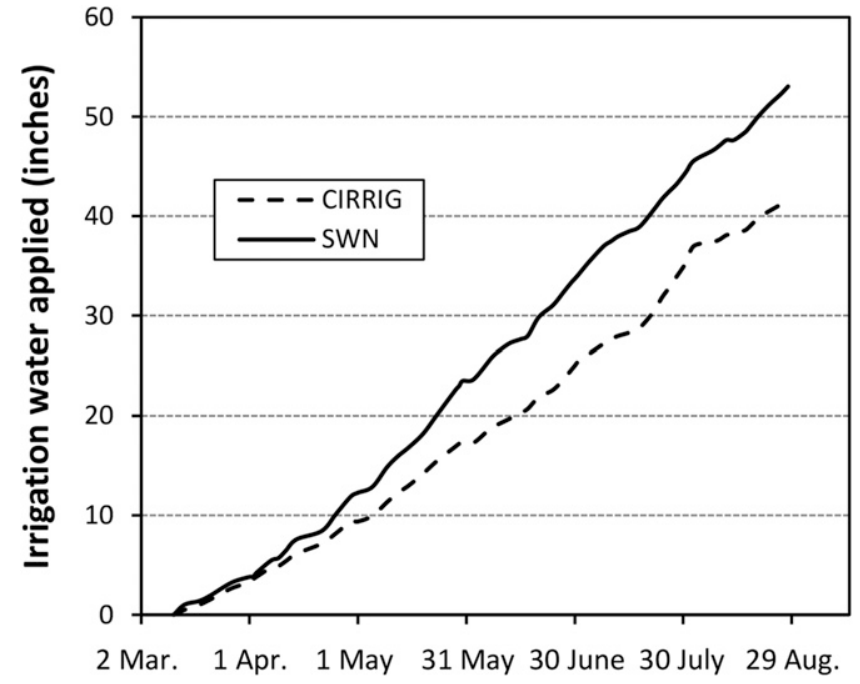

Fig. 5. Cumulative depth of water applied during the production of sweet viburnum in 10-inch-diameter containers irrigated automatically with a weather-based irrigation program (CIRRIG) or manually according to the nursery's traditional irrigation practice $(S W N) ; 1$ inch $=2.54 \mathrm{~cm}$.

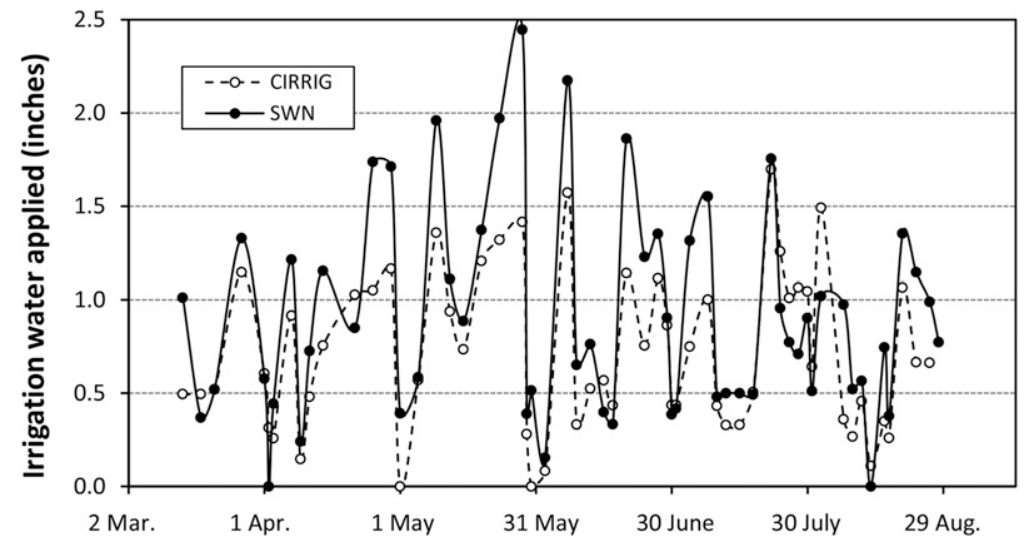

Fig. 6. Depth of water applied for each time interval between flowmeter readings during the production of sweet viburnum in 10-inch-diameter containers irrigated automatically with a weather-based irrigation program (CIRRIG) or manually according to the nursery's traditional irrigation practice $(S W N) ; 1$ inch $=2.54 \mathrm{~cm}$.

it rained $<0.5$ inch, $79 \%$ ( 4.7 vs. 6.0 inches) of rain directly reduced irrigation. The take-home message is that accounting for rain in a sprinkler irrigation program requires an objective accounting of when the rain fell and what amount actually got into the container relative to the container substrate's water deficit to estimate the rain's effectiveness for decreasing the irrigation requirement.

This trial demonstrated that CIRRIG can be used to effectively guide irrigation. Although the scope of this trial was limited, it provides evidence that when automated, daily adjustments to irrigation based on estimated ET and effective rain can conserve irrigation water without reducing plant growth. CIRRIG requires the user to monitor and input plant production conditions in the irrigation zone and as such requires active involvement by nursery staff to make it work. CIRRIG is being used to automatically irrigate $\approx 160$ zones of sprinkler-irrigated container production in a container nursery in VA. Staff at the nursery adopted several measures, which have helped them implement CIRRIG. For monitoring PPC, the staff visually compares the existing plant cover to a palette of images representing a range of PPC values and selects the one that best represents the existing condition. Another example is that pruning schedules and pruning specifications (e.g., plant height and width) are forwarded to the irrigation manager to input into CIRRIG. Similarly, spacing schedules are forwarded to the irrigation manager to input into CIRRIG. To save time, the effects of pruning and spacing on PPC can be estimated and input at the same time. Finally, leaching fraction testing (Stanley, 2012) can be conducted periodically throughout the nursery to ensure CIRRIG is performing effectively. Saunders Brothers (Piney River, VA) estimated that $10 \mathrm{~h} /$ week are devoted to day-to-day management of CIRRIG (J. Stanley, personal communication).

The cost for adopting CIRRIG technology at a nursery will depend on the cost of the two main components: CIRRIG and the computercontrolled irrigation system. The rights to CIRRIG are owned by the University of Florida and we have just begun investigating opportunities to offer the program to interested growers. We envision that future users will enter into an annual subscription agreement with UF that includes upfront training costs to ensure the nursery is using CIRRIG properly. The CIRRIG subscription would cover technical support as well as maintenance and program improvements. We estimate an annual subscription will cost $\approx \$ 10,000$, which will vary depending on nursery size and number of consulting trips needed.

The second component is the installation of a computer-controlled irrigation system and this cost will vary tremendously based upon nursery size, complexity, pumping challenges, local network upgrades, and other features (e.g., fertilizer or chlorine injection). The irrigation control contractor that installed the PLC system at Saunders Brothers nursery indicated that a 32 -valve control box with control software and network connectivity would cost $\approx \$ 8000$ to $\$ 10,000$ (R. Illig, personal communication). Additional costs for installation, programming, technical support are unknown but will certainly be higher during the first few years as the "kinks" get worked out.

We believe several conditions are needed to make a CIRRIG work effectively at any given nursery. The staff must be dedicated to the idea of weather-based irrigation. Automated CIRRIG technology is not a "set and 

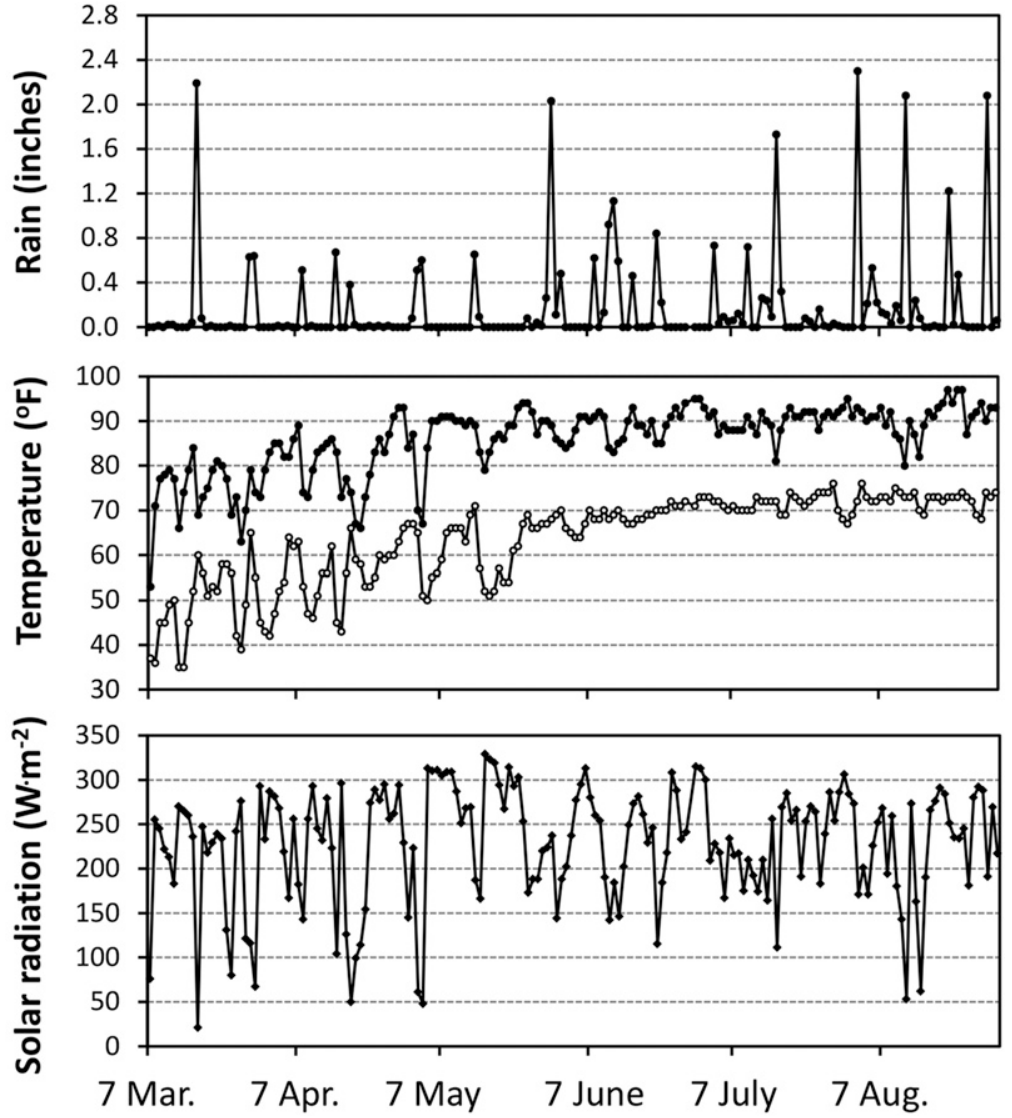

Fig. 7. Solar radiation, minimum and maximum temperatures, and daily rain recorded during the irrigation trial by a weather station located on-site; 1 inch = $2.54 \mathrm{~cm},\left({ }^{\circ} \mathrm{F}-32\right) \div 1.8={ }^{\circ} \mathrm{C}, 1 \mathrm{~W} \cdot \mathrm{m}^{-2}=0.0929 \mathrm{~W} / \mathrm{ft}^{2}$.

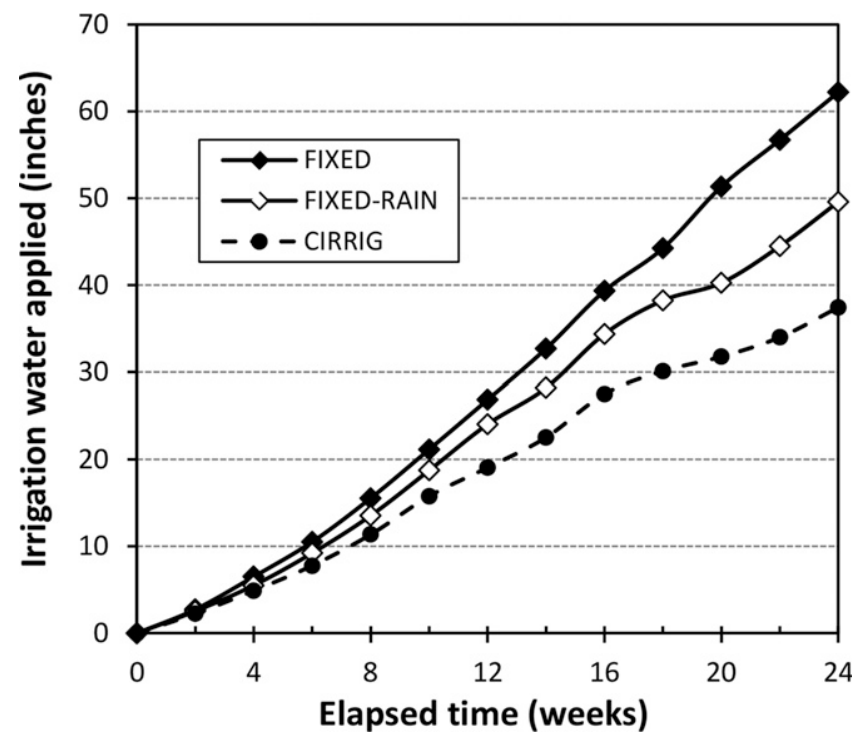

Fig. 8. Cumulative water use by a daily adjusted, weather-based irrigation schedule (CIRRIG) compared with two hypothetical fixed-rate schedules. For FIXED, the maximum daily amount of water applied by CIRRIG for a given 2-week interval was applied each day during that 2 -week interval. The FIXED-RAIN schedule was the same as FIXED except no irrigation was applied if 0.5 inch or more of rain fell during the past day; 1 inch $=2.54 \mathrm{~cm}$.

forget it" system like a traditional irrigation controller that is set manually. Staff must be dedicated to

managing CIRRIG inputs and outputs on a daily basis as well as ensuring irrigation effectiveness by diligent monitoring of plants in the field. It is also important that the nursery have good IT support to troubleshoot networking and computer problems that can often arise during power outages or following irrigation system malfunctions. On the production side, CIRRIG will be more effective if plants within irrigated areas have similar irrigation requirements; a nursery with diverse plantings within the same zone will not likely benefit greatly from CIRRIG. CIRRIG assumes the irrigation system provides relatively uniform delivery of water over the irrigated area and that application rates are consistent from one day to another. A container nursery that meets the above conditions and that is dedicated to irrigating efficiently should find that CIRRIG is a viable tool for implementing weather-based irrigation at the nursery.

\section{Literature cited}

Beeson, Jr., R.C. 2010. Modeling actual evapotranspiration of Viburnum odoratissimum during production from rooted cuttings to market size plants in 11.4-L containers. HortScience 45:12601264.

Beeson, Jr., R.C. 2005. Modeling irrigation requirements for landscape ornamentals. HortTechnology 15:18-22.

Belayneh, B.E., J.D. Lea-Cox, and E. Lichtenberg. 2013. Costs and benefits of implementing sensor-controlled irrigation in a commercial pot-in-pot nursery. HortTechnology 23:760-769.

Burt, C.M., A.J. Clemmens, and K.H. Strelkoff. 1997. Irrigation performance measures: Efficiency and uniformity. J. Irrig. Drain. Eng. 123:423-442.

GNU Image Manipulation Program. 2015. GIMP V2.8. 30 June 2015. <http:// www.gimp.org/>.

Grant, O.M., M.J. Davies, H. Longbottom, and R. Harrison-Murray. 2012. Evapotranspiration of container ornamental shrubs: Modelling crop-specific factors for a diverse range of crops. Irrig. Sci. 30:1-12.

Irmak, S. 2005. Crop evapotranspiration and crop coefficients of Viburnum odoratissimum (Ker.-Gawl). Appl. Eng. Agr. 21:371-381.

Kohanbash, D., G. Kantor, T. Martin, and L. Crawford. 2013. Wireless sensor network design for monitoring and irrigation control: User-centric hardware and 
software development. Hort Technology 23:725-734.

Million, J.B. and T.H. Yeager. 2015. Capture of sprinkler irrigation water by container-grown ornamental plants. HortScience 50:442-446.

Million, J.B., T.H. Yeager, and J.P. Albano. 2010. Evapotranspiration-based irrigation scheduling for reducing runoff during production of Viburnum odoratissimum (L.) Ker Gawl. HortScience 45:1741-1746.

Million, J.B., J.T. Ritchie, T.H. Yeager, C.A. Larsen, C.D. Warner, and J.P. Albano. 2011. CCROP - Simulation model for container-grown nursery plant production. Sci. Hort. 130:874-886.
Pardossi, A., L. Incrocci, G. Incrocci, F. Tognoni, and P. Marzialetti. 2008. What limits and how to improve water use efficiency in outdoor container cultivation of ornamental nursery stocks. Acta Hort. 843:73-80.

Playan, E., R. Salvador, J.M. Faci, N. Zapata, A. Martınez-Cob, and I. Sanchez. 2005. Day and night wind drift and evaporation losses in sprinkler solid-sets and moving laterals. Agr. Water Mgt. 76:139-159.

Ritchie, J.T. 1972. Model for predicting evapotranspiration from a row crop with incomplete cover. Water Resour. Res. 8:1204-1213.
Schuch, U.K. and D.W. Burger. 1997. Water use and crop coefficients of woody ornamentals in containers. J. Amer. Soc. Hort. Sci. 122:727-734.

Stanley, J. 2012. Using leaching fractions to maximize irrigation efficiency. Intl. Plant Prop. Soc. 62:331-334.

University of Florida. 2015. CIRRIG. 6 June 2015. <http://www.bmptoolbox. org / cirrig/>.

van Iersel, M.W., M. Chappell, and J.D. Lea-Cox. 2013. Sensors for improved efficiency of irrigation in greenhouse and nursery production. HortTechnology 23:735-746. 